\title{
Viewing BCL2 and cell death control from an evolutionary perspective
}

\author{
Andreas Strasser ${ }^{*, 1,2}$ and David L Vaux ${ }^{*, 1,2}$
}

The last 30 years of studying BCL2 have brought cell death research into the molecular era, and revealed its relevance to human pathophysiology. Most, if not all metazoans use an evolutionarily conserved process for cellular self destruction that is controlled and implemented by proteins related to BCL2. We propose the anti-apoptotic BCL2-like and pro-apoptotic BH3-only members of the family arose through duplication and modification of genes for the pro-apoptotic multi-BH domain family members, such as BAX and BAK1. In that way, a cell suicide process that initially evolved as a mechanism for defense against intracellular parasites was then also used in multicellular organisms for morphogenesis and to maintain the correct number of cells in adults by balancing cell production by mitosis.

Cell Death and Differentiation (2018) 25, 13-20; doi:10.1038/cdd.2017.145; published online 3 November 2017

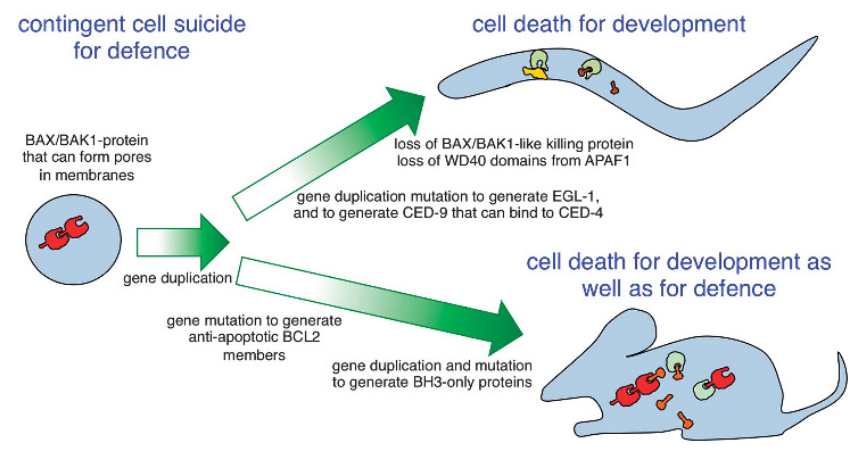

Graphical Abstract

Facts

- The function of BCL2, which is one member of a family of proteins, is to inhibit cell suicide.

- Failure of BCL2-regulated cell death can promote cancer and autoimmune disease.

- Not all programmed cell death pathways, and not even all apoptosis, can be inhibited by BCL2.

- Cell death pathways are evolutionarily conserved - but not completely.

- Anticancer therapeutics act (at least in part) by activating the BCL2-regulated cell death pathway.

\section{Open Questions}

- Are there any BCL2 or BAX/BAK1 ancestors in protozoans, fungi or plants?

- What is the overall role of the different cell death processes in mammalian embryonic development?
- How are the initiators of apoptosis, the BH3-only proteins, regulated?

- How should BH3 mimetic drugs be combined with other cancer therapies?

- Will MCL1 inhibitors have a useful therapeutic index?

All living things are made of cells, and each of them carries the genetic material needed for their reproduction. Generation after generation, the genomes of our ancestors were refined through natural selection to allow all of them, without exception, to survive long enough to reproduce. It is therefore somewhat surprising that evolution also allowed generation of a molecular mechanism whose role is not cell survival, but the opposite - cell suicide. Even though cell suicide has been recognized for over 150 years, and is vital for our development and well-being, an understanding of the molecular mechanisms by which our cells kill themselves was only achieved in the last 30 years. This review will look at the BCL2 family of proteins, their functions in regulating and implementing the cell death program, and it speculates on how the members of this family may have evolved.

\section{The Function of BCL2: The First Molecular Clue into Cell Death Mechanisms}

The BCL2 gene was discovered because chromosomal translocations involving the $B C L 2$ locus frequently occur in certain human lymphomas. Rowley was looking for correlations between particular chromosomal translocations and various types of human leukemias and lymphomas, and found the $t$ $[14 ; 18]$ translocation frequently occurred in a type of blood cancer, the follicular center B-cell lymphoma. ${ }^{1}$ Tsujimoto et al. ${ }^{2}$ in Carlo Croce's lab first cloned the chromosomal breakpoint and then the affected gene on chromosome 18, which they termed BCL2 for 'B-cell leukemia/lymphoma gene number 2'.

\footnotetext{
${ }^{1}$ The Walter and Eliza Hall Institute of Medical Research, Parkville, Victoria, Australia and ${ }^{2}$ Department of Medical Biology, University of Melbourne, Parkville, Victoria, Australia

${ }^{*}$ Corresponding author: DL Vaux or A Strasser, The Walter and Eliza Hall Institute of Medical Research, 1G Royal Parade, Parkville, Victoria 3052 , Australia. Tel.: +61-3-9345-2555; Fax: +61-3-9347-0852; E-mail: vaux@wehi.edu.au or strasser@wehi.edu.au Received 29.4.17; revised 14.6.17; accepted 03.8.17; Edited by F Pentimalli; published online 03.11.17
} 


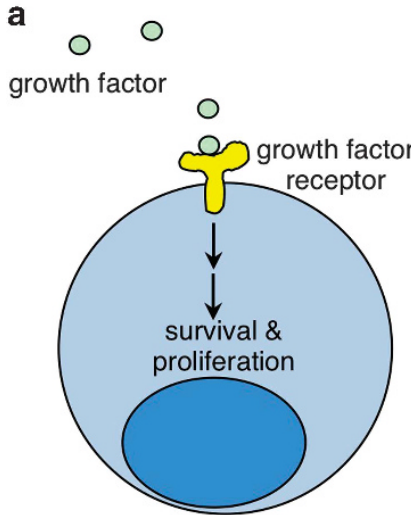

b

O growth factor not

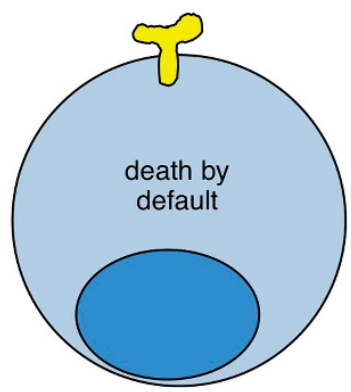

C

○

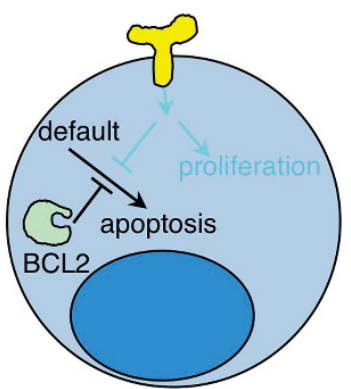

d

$\bigcirc \bigcirc$

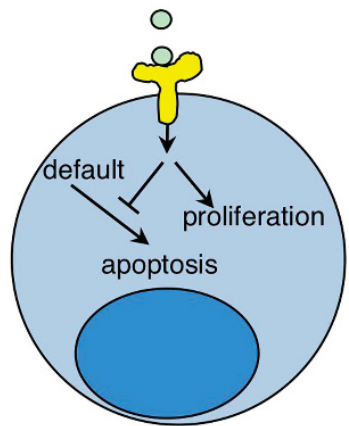

Figure 1 Separate growth factor receptor-activated pathways regulating cell division and cell survival. Ligation of growth factor receptors was known to signal survival and proliferation (a and $\mathbf{b}$ ). Enforced expression of BCL2 (c) showed that growth factor receptors control independent mechanisms for cell proliferation and cell survival/cell death (d). These experiments showed that BCL2 inhibited cell death, but had no impact on cell division

A full-length $B C L 2$ cDNA (first for human and then also for mouse) was also cloned by Tsujimoto, and independently by Cleary in Jeffrey Sklar's lab. ${ }^{3,4}$ Efforts then began to confirm whether BCL2 was, as suspected, an oncogene that had a role in causing lymphoma, as well as to determine its function in normal cells. BCL2's sequence did not provide many clues - it did not bear any known structural motifs, and the only known gene with similar sequence was one of then unknown function from Epstein-Barr virus, BHRF1. ${ }^{4}$

The ability of BCL2 to promote cancer, and its function in normal cells, namely to prevent them from killing themselves, were discovered by enforcing expression of a BCL2 cDNA in growth factor-dependent myeloid and lymphoid progenitor cell lines (Figure 1). ${ }^{5}$ Unlike some other oncogenes known at the time (e.g., $v-A b /$ ), enforced expression of BCL2 did not stimulate cell growth and proliferation when growth factors were removed. BCL2 had a different and unique effect; it prevented cells from killing themselves when growth factors were withdrawn. Rather than dying, they persisted in the quiescent $\mathrm{G}_{0}$ state of the cell cycle. When growth factor was returned to the cultures, these 'saved' cells began to grow and proliferate once more. Although on its own enforced BCL2 expression was incapable of transforming normal cells to full

malignancy, its ability to prevent the suicide of oncogenically stressed cells enabled it to potently synergize with conventional growth-promoting oncogenes, such as $c-M y c$ or $v-A b /$ to generate malignant cells both in vitro and in vivo. ${ }^{5,7-10}$

Because aberrant expression of BCL2 was associated with lymphoma, these experiments linked inhibition of cell suicide with malignancy in humans, implicating a novel oncogenic mechanism. They also provided the first molecular handle into the molecular mechanism of apoptosis, and demonstrated that growth factor receptor-driven promotion of cell proliferation versus cell survival are subject to distinct control, with only the latter affected by BCL2.

Although the fact that cells in animals can kill themselves under certain circumstances had already been recognized for over a century, the term 'apoptosis' for this process was only adopted by Kerr et al. ${ }^{11}$ However, interest in apoptosis remained low until the discovery of the molecular mechanism, beginning with BCL2.

\section{Cell Death Mechanisms Across Species: Insights from the Worm}

Cell death research was also progressing independently using invertebrate models. By the late 1980s, Sulston, Horvitz and colleagues had assembled a collection of mutant worms that allowed them to deduce a genetic pathway specific for the programmed cell deaths that occur during development of the nematode Caenorhabditis elegans. ${ }^{12}$ However, the genes involved were not cloned until the 1990s, so at that time the nature of the proteins encoded and how they functioned in cell killing was unknown. Furthermore, it was not clear whether there was anything in common between the mechanism for programmed cell death in the worm and the mechanism for apoptosis of mammalian cells.

The experiment that showed that programmed cell death in worms and apoptosis in human cells were implemented by similar, evolutionarily conserved, mechanisms was expression of a human BCL2 transgene in $C$. elegans. ${ }^{13}$ Because human BCL2 was able to reduce the amount of programmed cell death occurring during development of worm embryos, human BCL2 protein must have been able to engage with, and inhibit, the worm's cell death machinery. Furthermore, this experiment implied that the way to find out how BCL2 prevented apoptosis of mammalian cells was to clone the worm's cell death genes, and then find their homologs in mammals. Cloning of the $C$. elegans cell death genes by Horvitz and his colleagues confirmed that the mechanism of programmed cell death was conserved between worms and humans, and illuminated the pathway for cell death in both nematodes and mammals. ${ }^{14,15}$

The ced-9 gene in the worm, which was known to encode a cell death inhibitor, ${ }^{15,16}$ was found to have a sequence similar to that of human BCL2, confirming that they are homologs. Furthermore, transgenic studies revealed that human BCL2 could not only function in the worm, ${ }^{13}$ but was even able to compensate (albeit incompletely) for the loss of CED-9 function. ${ }^{15}$ The $C$. elegans killer gene ced-3 encoded a protein that resembled the then already known mammalian cysteine protease interleukin $1 \beta$-converting enzyme, now termed caspase-1, ${ }^{14,17,18}$ and a mammalian homolog for the CED-3- 

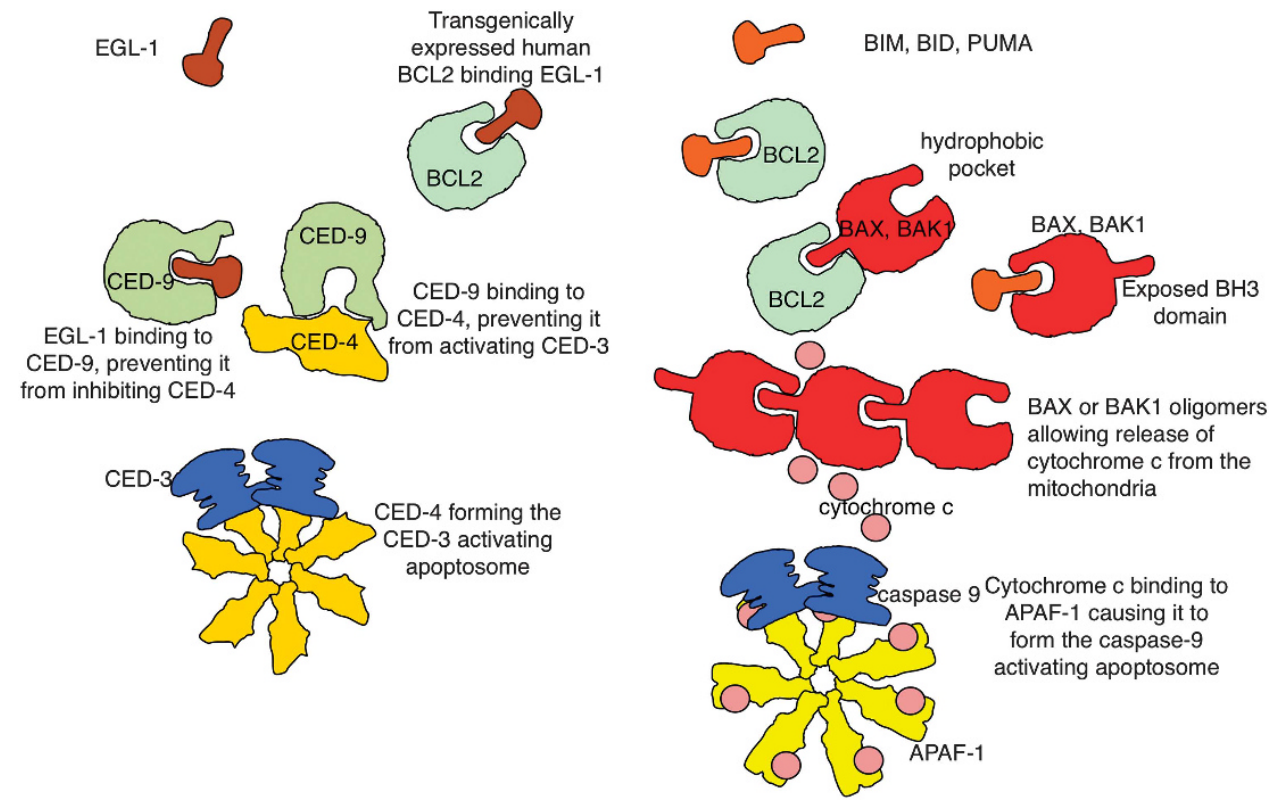

Figure 2 Comparison of pathways for programmed cell death in C. elegans and apoptosis in mammalian cells. Key differences are that in C. elegans anti-apoptotic CED-9 causes cell survival by preventing activation of CED-4, the activator of the caspase, CED-3, whereas in mammalian cells pro-survival BCL2 inhibits apoptosis by preventing activation of BAX/BAK1 and by neutralizing BH3-only proteins. When expressed in C. elegans, human BCL2 prevents cell death by binding to the BH3-only protein EGL-1, but cannot bind to CED-4 and prevent it activating the caspase CED-3. To block cell death in C. elegans, human BCL2 requires the presence of residual CED-9

activating adaptor protein CED- $4^{19}$ was found with the purification and identification of the caspase-9-activating adaptor APAF1. ${ }^{20}$

The research on cell death in $C$. elegans suggested that BCL2 would act in mammalian cells as CED-9 does in the worm, namely to promote cell survival by somehow preventing the activation of caspases. This was a major step forward, and shows the value of research on model organisms. Nevertheless, although they are similar, and both cell death processes evolved from the same ancestral mechanism, there are key differences between the way CED-9 inhibits cell death in the worm, and how BCL2 inhibits the apoptotic death of mammalian cells. ${ }^{21}$ For example, later work showed that CED-9 directly binds to the adaptor protein CED-4, to prevent it activating the caspase CED-3, but that the protein EGL-1 also binds to CED-9, and can promote cell death by displacing CED-4. When expressed in the worm, human BCL2 acts as a sink by binding pro-apoptotic EGL-1, but human BCL2 cannot bind to and inhibit CED-4. In the worm, therefore, BCL2 inhibits cell death by reducing the amount of EGL-1 that is free to bind to CED-9. ${ }^{22}$

Using techniques such as the yeast-two-hybrid method, lambda phage expression library screening, and coimmunoprecipitation, researchers looked for proteins that could bind to BCL2. Korsmeyer's group identified a protein that resembled BCL2 in having several BCL2 homology $(\mathrm{BH})$ domains, but instead of promoting cell survival, this protein, they called BAX, had the opposite function - it enhanced cell killing under conditions of stress. ${ }^{23}$ It is now clear that the pathway for death of mammalian cells that can be blocked by BCL2 requires the presence of BAX, or its close relative, $\mathrm{BAK} 1,{ }^{24}$ whereas a similar death- promoting activity is not involved in developmental programmed cell death in the worm.

When free from inhibition by BCL2, or related pro-survival family members (i.e., BCLXL, MCL1, A1/BFL1, and BCLW), the pro-apoptotic multi-BH domain proteins $\mathrm{BAX}$ and BAK1 can become activated to cause mitochondrial outer membrane permeabilization (MOMP) that allows the release of mitochondrial proteins, such as cytochrome c (see review by $\mathrm{Green}^{25}$ in this volume). Once in the cytoplasm, cytochrome c can bind to the WD40 domains of APAF1, the homolog of C. elegans CED-4. This allows APAF1 to activate caspase$9,^{20,26}$ a so-called initiator caspase that functions as a homolog of $C$. elegans CED-3. Therefore, in mammals, BAX and BAK1 are the key effectors of apoptosis; MOMP is the point of no return for dying cells; and in contrast to CED-4/ CED-3 from $C$. elegans, the APAF1/caspase- 9 apoptosome is not essential for cell death, but has a role in efficient, immunologically silent, disposal of the cell's constituents. ${ }^{27-29}$ In C. elegans there is no BAX/BAK1-like protein, and CED-9 promotes cell survival by binding directly to the adaptor protein CED-4, thereby preventing it from activating the caspase CED$3,^{30}$ Thus, in $C$. elegans there is no role for a BAX/BAK1-like function in programmed cell death, no role for cytochrome $\mathrm{c}$ in caspase activation, and caspase activation, rather than MOMP, is the point of no return.

Although the steps downstream of BCL2 versus CED-9 in cell death differ between mammals and nematodes, the steps immediately upstream are very similar (Figure 2). Mammalian pro-survival BCL2 family members can be inhibited by proapoptotic BH3-only proteins, which are so-called because they bear an alpha-helical region that resembles that of the $\mathrm{BH}$ region $3(\mathrm{BH} 3)$, but have no other resemblance to other $\mathrm{BCL} 2$ 


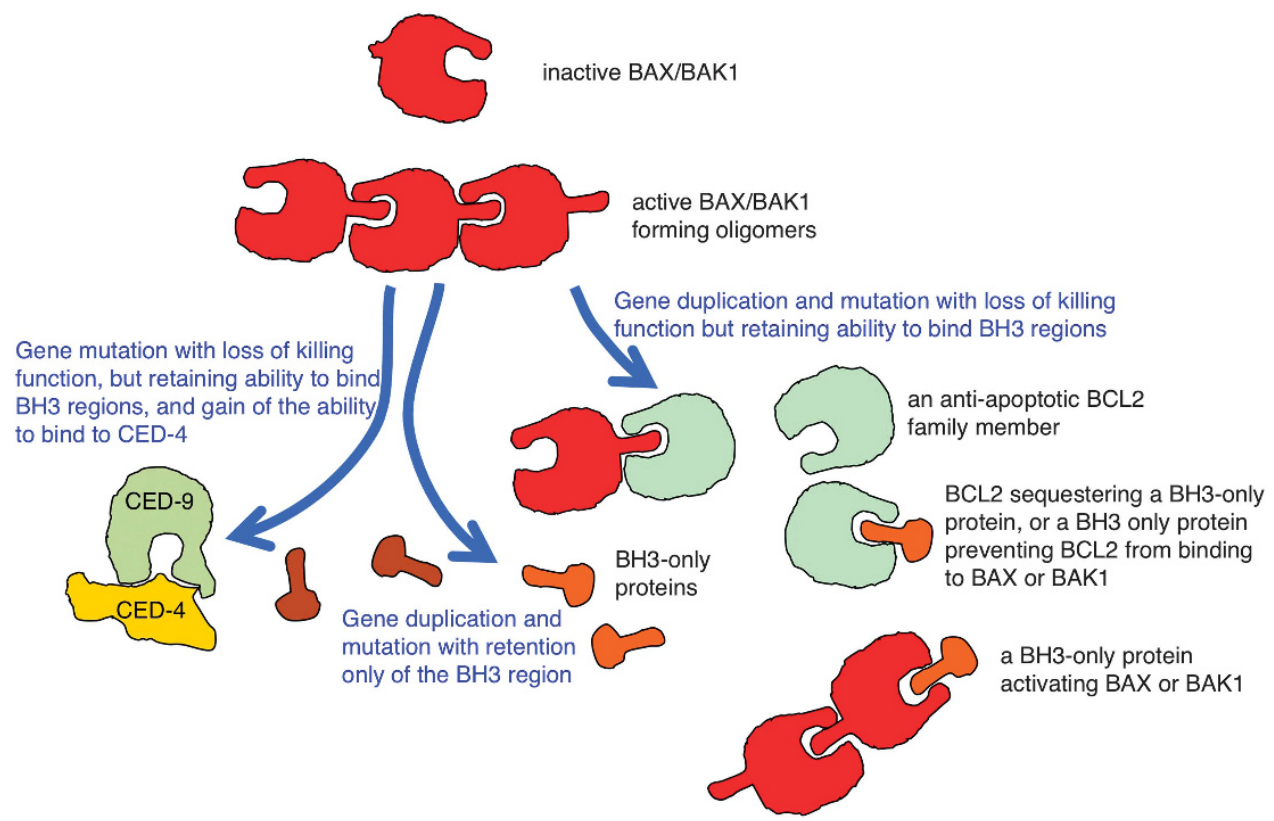

Figure 3 Speculative evolution of the BCL2 protein subfamilies. The first members were like pro-apoptotic BAX and BAK1, and had three functions: exposing a BH3 domain; binding a BH3 domain of another protein; and forming oligomers that could act as channels allowing proteins to cross membranes. Anti-apoptotic family members (such as BCL2 itself) arose by gene duplication from a BAX/BAK1-like ancestor, and mutations that caused the protein to lose its ability to expose its BH3 domain in a way that higher-order multimers could form, whilst retaining its ability to bind to the BH3 domains of other proteins, such as BAX and BAK1. In this way, anti-apoptotic BCL2 family members act as dominant negative versions of BAX and BAK1. BH3-only family members arose as proteins that could bind to anti-apoptotic BCL2 family members to unleash BAX or BAK1, or could bind to BAX or BAK1 to activate them directly, in both ways triggering formation of multimers. Cartoons are diagrammatic only

family members. ${ }^{31}$ Binding of a BH3-only protein, such as $\mathrm{BIM},{ }^{32,33} \mathrm{PUMA}^{34-36}$ or activated tBid, ${ }^{37}$ to $\mathrm{BCL} 2$ or its prosurvival relatives (BCLXL, MCL1, $A 1 / B F L 1$, and $B C L W)$ can unleash the killing activity of $B A X$ and $B A K 1$ so that they are no longer inhibited and are free to cause cell death. In a similar way, $C$. elegans bears a gene for a $\mathrm{BH} 3-$ only protein that we have already met, EGL-1, that can bind to pro-survival CED-9 and prevent it from inhibiting CED-4, which is then free to activate the caspase CED-3. ${ }^{38}$

A recent study using CRISPR/Cas9 technology to delete the genes for all BCL2 family members in two human cancerderived cell lines has shown that reintroduced BAX or BAK1 can activate spontaneously (even in the absence of all recognized $\mathrm{BH}$ 3-only proteins) when all pro-survival BCL2 family members are absent. ${ }^{39}$ This is consistent with a model in which $\mathrm{BH}$-only proteins induce apoptosis mainly by binding the pro-survival BCL2-like proteins, thereby blocking their ability to restrain $B A X$ and $B A K 1$, although it remains possible that in cells expressing all three subgroups of the BCL2 family, certain $\mathrm{BH} 3-$ only proteins may also directly activate $\mathrm{BAX}$ and BAK1. ${ }^{40,41}$

The shared motifs and interconnected functions suggest how the three subtypes of BCL2 family members might have evolved (Figure 3 ). If there was an original BCL2like protein that functioned like BAX or BAK1, then duplication of the genes followed by mutations that blocked the killing function would have generated proteins that act as dominant negative inhibitors of BAX/BAK1's killing function, that is, resulting in BCL2/CED-9-like prosurvival proteins. Further duplication of BCL2 family genes, followed by different mutations that removed all conserved regions except the $\mathrm{BH} 3$ domain, could have yielded proteins that retain the ability to bind to pro-survival BCL2 family members, and could thereby displace and free the cell death executioners BAX/BAK1. At least some of these $\mathrm{BH} 3-$ only proteins might also have retained the ability to bind to and thereby directly trigger activation of BAX/BAK1 to induce cell death, even though on their own, they could not kill cells. Interestingly, full-length BID is the only $\mathrm{BH} 3$-only protein that has a long half-life and has a structure that closely resembles that of BAX/BAK1, indicating that it still retains $\mathrm{BH} 1, \mathrm{BH} 2$, and $\mathrm{BH} 4$ folds/ domains. $^{42}$ BID only assumes pro-apoptotic BH3-only protein function after its cleavage by caspase-8 (and possibly certain other caspases) into tBID. ${ }^{43,44}$ It is tantalizing to speculate that an ancestral form of fulllength BID, similar to $\mathrm{BOK},{ }^{45-47}$ may have had a $\mathrm{BAX} /$ BAK1-like killing function.

If the ancestral BCL2 family protein was like pro-apoptotic $\mathrm{BAX}$ or BAK1, duplication and loss of killing functions could have generated the anti-apoptotic BCL2 family members. Evolution of $C$. elegans CED-9 from an ancestral BAX- or BAK1-like protein would have required not only loss of its ability to oligomerize to form a membrane channel ${ }^{48,49}$ but also gain of the ability to bind to and inhibit CED-4. It would be interesting to know whether the ability of CED-4 to activate caspases without the need to be triggered by cytochrome $c$ arose before or after CED-9 acquired the ability to bind to CED-4. 


\section{Cell Death Throughout Evolution: from a Defense Strategy to a Tailoring Tool for Development and Homeostasis}

Although there are key differences, the striking conservation of the mechanisms for apoptosis between nematodes and mammals, and the finding of similar genetic pathways involving BCL2 family members, caspases, and their adaptors among other metazoan phyla, such as sponges, molluscs, arthropods, and helminths, raises the possibility that apoptosis evolved very early in metazoan evolution, and perhaps even earlier, in the protozoa. ${ }^{50,51}$

While it initially seems counter-intuitive to think that a mechanism for cell suicide could have evolved in a singlecelled organism, because once the mechanism was activated, the genes could not be passed on from the dying cell, it is plausible that cell death arose in a community of single-celled organisms as a defense strategy against intracellular parasites. While triggering of the cell death mechanism by an infected cell would prevent that particular cell from passing on its genes, the rest of the community that shared the same (or highly related) genes would be advantaged compared to communities of cells that could not kill themselves by being able to resist the spread of infection. ${ }^{52,53}$

There are several observations that are consistent with the notion that apoptosis (and additional cell death processes) initially evolved as a defense strategy that was later duplicated and adapted to be used for organismal development, and to maintain correct cell numbers by balancing mitotic cell division. First, certain caspases, most notably caspase-1 and caspase-11, are activators of pro-inflammatory cytokines, such as IL-1 $\beta$ and IL-18, suggesting that defensive cell death could be pro-inflammatory, such that the immune system was alerted and primed to fight the infection. ${ }^{17,18,54}$ Second, many viruses carry genes for cell death inhibitors, including ones resembling pro-survival BCL2. Indeed, the first BCL2-like gene to be identified was BHRF1 from Epstein-Barr virus (see above), and subsequently BCL2 homolog have also been found in herpesviruses, adenoviruses, and African swine fever virus, among others. ${ }^{52}$ Similarly, some viruses carry genes for caspase inhibitors. ${ }^{55,56}$ Presumably, viruses that have captured genes for cell death inhibitors are advantaged because they can use them to prevent demolition of the cell until after viral replication has taken place. ${ }^{57-59}$

The broad existence of the BAX/BAK1-dependent cell death mechanism among the metazoans, and the possibility that this mechanism might have arisen as an altruistic suicide strategy to prevent the spread of infection by an intracellular parasitic microorganism within a community of cells, might help explain why BAX/BAK1 cause cell death by targeting mitochondria. Early in eukaryotic evolution, a prokaryote was engulfed by an early eukaryotic cell, and the prokaryote gradually developed into a mitochondrion. Thus, a BAX/BAK1like ancestral protein that initially evolved to protect the early eukaryotic cell by puncturing invading bacteria might subsequently have been co-opted to cause suicide of the host cell by destroying their mitochondria. On the other hand, the absence of BCL2 family members in plants and fungi argues that if they arose in a single-celled organism, it was a protozoan, after the split between the animal and plant kingdoms, or that the genes were subsequently lost in plants.

Once anti-apoptotic BCL2 family members had evolved from duplicated and mutated BAX/BAK1-like genes, they would have been available for capture by viruses, which would have allowed the viruses in turn to protect themselves against defensive suicide of the infected host cell.

If such a scenario arose, there would, of course, have been selective pressure for host organisms to come up with cell death mechanisms that can bypass or override the blocks caused by viral pro-survival BCL2-like proteins. Indeed, it was the search for cases of apoptosis that could not be blocked by BCL2 (or its pro-survival relatives) that provided the first evidence for cell death pathways that can operate independently of the BCL2 family.

For example, one of the major defenses of vertebrates against viruses are cytotoxic $\mathrm{T}$ cells $(\mathrm{CTL})$ that can cause death of infected target cells. That CTL-mediated killing, which is mediated in part by perforin and granzymes, ${ }^{60}$ was not blocked by the overexpression of BCL2 in the target cells provided evidence that there was more than one pathway to apoptosis, and that some could not be blocked by BCL2. ${ }^{61,62}$ The fact that in some cell types BCL2 could block apoptosis induced by a variety of agents but not by ligation of the 'death receptor' FAS (CD95/APO-1) provided further evidence of distinct, independent pathways to apoptosis, only some of which involved BCL2 family members. ${ }^{63,64}$ Notably, in certain cells (called type 2), such as hepatocytes or pancreatic $\beta$ cells, BCL2 (or its pro-survival relatives) can inhibit FASL/FASinduced apoptosis, because efficient cell killing requires the death receptor pathway (reliant on caspase-8) to engage the BCL2-regulated (mitochondrial) apoptotic pathway by proteoIytic activation of BID to tBID. ${ }^{65-67}$

The generation of double-knockout mice deficient for both perforin and FASL revealed that the perforin/granzyme and 'death receptor' pathways account for most if not all killing activity of CTLs. This is demonstrated, for example, by the observation that $T$ cells from these double-knockout mice are unable to elicit acute, lethal, graft versus host disease in recipient animals. ${ }^{68,69}$

\section{Cell Death with, and without, Inflammation}

With the evolution of multicellularity in animals, there would have been other circumstances, in addition to removal of infected cells, when cell suicide would have been useful. In multicellular organisms with separate germ cell and somatic cell lineages, death of superfluous somatic cells could be programmed, so that it was a cell fate, rather than cell death purely being a contingent process. Regulation of programmed cell death would have been facilitated by duplication and mutational adaptation of the functions of the genes encoding the components of the cell death machinery. Where cell death is used as a program, such as to remove superfluous skin cells or unconnected neurons during development, or to balance cell production by mitosis, inflammation would not be required, and would in fact often be detrimental to the organism. ${ }^{11,70}$ The fact that transgenic expression of BCL2 caused an inflammatory autoimmune disease resembling SLE provided 
evidence that apoptosis is needed to control immune responses. $^{71}$

In contrast, when cells are killing themselves upon detection of an infecting microorganism, inflammation would be desirable to alert neighboring cells to mount an immune response. Such a scenario might explain the existence of caspases, such as caspase- 1 and caspase-11, that process and activate pro-inflammatory cytokines, such as IL- $1 \beta$ and IL-18 ${ }^{17,18}$ as mentioned above, and also trigger the highly pro-inflammatory pyroptotic cell death pathway through proteolytic activation of gasdermin D. ${ }^{72,73}$ In contrast, the initiator caspase, caspase9 , and the downstream effector caspases -3 and -7 (and possible also -6), which help dismantle a cell after BAX/BAK1mediated cell death, operate in an immunologically silent manner. These caspases not only do not activate proinflammatory cytokines, they also actively prevent induction of inflammation when mitochondrial DNA is released into the cytoplasm of dying cells. ${ }^{29,74}$

\section{Cell Death to Cope with Damage and Stress: Implications for Cancer Therapy}

The existence of cell death mechanisms that can be activated to remove cells that are unwanted, for example, because they have fulfilled their function, could also have been useful to remove damaged cells. Under conditions of stress, for example, when an important metabolic or synthetic process cannot operate or is blocked, cells generally activate processes to restore homeostasis, such as by increasing expression of heat-shock proteins to refold denatured proteins, metallo-thioneins to bind toxic metals, or cell cycle inhibitors to delay DNA replication so that DNA lesions and

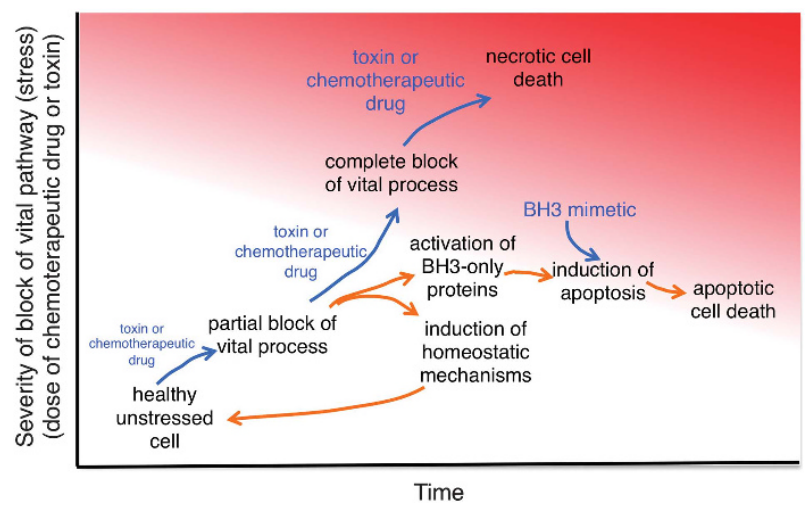

Figure 4 Cell suicide as a response to cell stress and chemotherapy -

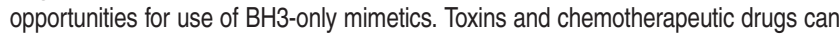
partially or completely interrupt vital processes causing cell stress (red color). Healthy cells have well-tuned homeostatic mechanisms, and can repair such damage, but if there is sufficient damage, they can trigger the apoptotic mechanism to kill themselves. Tumor cells with higher levels of anti-apoptotic BCL2 family members would resist apoptosis, and be at a selective advantage. A chemotherapeutic drug will be useful if it causes tumor cells to die either by direct toxicity or by inducing apoptosis, as long as it does not cause too many normal cells to die. BH3 mimetic drugs might act alone to cause death of tumor cells with high levels of anti-apoptotic BCL2 family proteins, and might synergize with chemotherapeutic drugs by decreasing their threshold for activation of apoptosis. The therapeutic index would be a function of the strength of the homeostatic mechanisms and the relative dependence on high levels of anti-apoptotic BCL2 family proteins other cellular damage can be repaired. ${ }^{75}$ Triggering of apoptosis is also a common response to cell stress, which helps to explain why apoptosis can be induced by such a wide variety of chemical and physical insults. The fact that cancer cells can respond to chemotherapy or radiation by undergoing apoptosis, and may do so at levels of insult below those required for the drug or treatment to kill the cell directly, has implications for how cancers are treated. On one hand, cancer cells that happen to express abnormally high levels of a prosurvival BCL2 family member would be rendered resistant to treatment with chemotherapy or radiation, ${ }^{61,76}$ but on the other

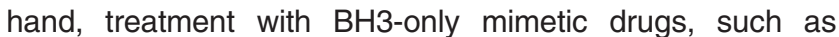
venetoclax/ABT-199 (inhibits $B C L 2^{77}$ ), navitoclax/ABT-263 (inhibits $\mathrm{BCL} 2, \mathrm{BCLXL}$, and $\mathrm{BCLW}^{78}$ ), or $\mathrm{S} 63845$ (inhibits MCL $1^{79}$ ), would be predicted to act synergistically with chemotherapy by lowering the threshold for cells to undergo apoptosis (Figure 4).

In conclusion, we propose that the evolution of the BCL2 family of proteins began with the executioners of apoptosis, the BAX/BAK1 proteins, plausibly in a unicellular organism, as a contingent, altruistic defense against pathogens. With the evolution of multicellular animals, and through gene duplication and mutation, this ancestral killing process evolved to also be used for development and homeostasis of cell number, such that even though the mechanisms for programmed cell death in $C$. elegans, and apoptosis of mammalian cells have key differences, they retain aspects that reflect their common origin.

\section{Conflict of Interest}

The authors declare no conflict of interest.

Acknowledgements. We thank all of our current and past colleagues, and support from the Australian National Health and Medical Research Council (Program Grant 1016701 to both DLV and AS and Fellowships 1020136 to DLV and 1020363 to AS), the Leukemia and Lymphoma Society of America (LLS SCOR 7001-13 to both DLV and AS), the Cancer Council of Victoria (1052309), as well as operational infrastructure grants through the Australian Government Independent Research Institute Infrastructure Support Scheme (9000220) and the Victorian State Government Operational Infrastructure Support Program.

1. Fukuhara S, Rowley JD. Chromosome 14 translocations in non-Burkitt lymphomas. Int $J$ Cancer 1978; 22: 14-21.

2. Tsujimoto Y, Finger LR, Yunis J, Nowell PC, Croce CM. Cloning of the chromosome breakpoint of neoplastic B cells with the $t(14 ; 18)$ chromosome translocation. Science 1984; 226: 1097-1099.

3. Tsujimoto Y, Jaffe E, Cossman J, Gorham J, Nowell PC, Croce CM. Clustering of breakpoints on chromosome 11 in human B-cell neoplasms with the $t(11 ; 14)$ chromosome translocation. Nature 1985; 315: 340-343.

4. Cleary ML, Smith SD, Sklar J. Cloning and structural analysis of cDNAs for bcl-2 and a hybrid bcl-2/immunoglobulin transcript resulting from the $t(14 ; 18)$ translocation. Cell 1986; 47: 19-28.

5. Vaux DL, Cory S, Adams JM. Bcl-2 gene promotes haemopoietic cell survival and cooperates with c-myc to immortalize pre-B cells. Nature 1988; 335: 440-442.

6. Cook WD, Metcalf D, Nicola NA, Burgess AW, Walker F. Malignant transformation of a growth factor-dependent myeloid cell line by Abelson virus without evidence of an autocrine mechanism. Cell 1985; 41: 677-683.

7. Strasser A, Harris AW, Bath ML, Cory S. Novel primitive lymphoid tumours induced in transgenic mice by cooperation between myc and bcl-2. Nature 1990; 348: 331-333.

8. Strasser A, Harris AW, Vaux DL, Webb E, Bath ML, Adams JM et al. Abnormalities of the immune system induced by dysregulated bcl-2 expression in transgenic mice. Curr Top Microbiol Immunol 1990; 166: 175-181.

9. Strasser A, Harris AW, Cory S. E mu-bcl-2 transgene facilitates spontaneous transformation of early pre-B and immunoglobulin-secreting cells but not T cells. Oncogene 1993; 8: 1-9. 
10. Vandenberg CJ, Waring P, Strasser A, Cory S. Plasmacytomagenesis in Emu-v-abl transgenic mice is accelerated when apoptosis is restrained. Blood 2014; 124: 1099-1109.

11. Kerr JF, Wyllie AH, Currie AR. Apoptosis: a basic biological phenomenon with wide-ranging implications in tissue kinetics. Br J Cancer 1972; 26: 239-257.

12. Ellis RE, Yuan JY, Horvitz HR. Mechanisms and functions of cell death. Annu Rev Cell Biol 1991; 7: 663-698.

13. Vaux DL, Weissman IL, Kim SK. Prevention of programmed cell death in Caenorhabditis elegans by human bcl-2. Science 1992; 258: 1955-1957.

14. Yuan JY, Shaham S, Ledoux S, Ellis HM, Horvitz HR. The C. elegans cell death gene ced 3 encodes a protein similar to mammalian interleukin 1 beta converting enzyme. Cell 1993; 75: 641-652.

15. Hengartner MO, Horvitz HR. C. elegans cell survival gene ced-9 encodes a functional homolog of the mammalian proto-oncogene bcl-2. Cell 1994; 76: 665-676.

16. Hengartner MO, Ellis RE, Horvitz HR. Caenorhabditis elegans gene ced-9 protects cells from programmed cell death. Nature 1992; 356: 494-499.

17. Cerretti DP, Kozlosky CJ, Mosley B, Nelson N, Van NK, Greenstreet TA et al. Molecular cloning of the interleukin-1 beta converting enzyme. Science 1992; 256: 97-100.

18. Thornberry NA, Bull HG, Calaycay JR, Chapman KT, Howard AD, Kostura MJ et al. A novel heterodimeric cysteine protease is required for interleukin-1 beta processing in monocytes. Nature 1992; 356: 768-774.

19. Yuan J, Horvitz HR. The Caenorhabditis elegans cell death gene ced-4 encodes a novel protein and is expressed during the period of extensive programmed cell death. Development 1992; 116: 309-320.

20. Zou H, Henzel WJ, Liu XS, Lutschg A, Wang XD. Apaf-1, a human protein homologous to c-elegans ced-4, participates in cytochrome c-dependent activation of caspase-3. Cell 1997; 90: 405-413.

21. Strasser A, O'Connor L, Dixit VM. Apoptosis signaling. Annu Rev Biochem 2000; 69: 217-245.

22. Jabbour AM, Puryer MA, Yu JY, Lithgow T, Riffkin CD, Ashley DM et al. Human Bcl-2 cannot directly inhibit the Caenorhabditis elegans Apaf-1 homologue CED-4, but can interact with EGL-1. J Cell Sci 2006; 119(Pt 12): 2572-2582.

23. Oltvai ZN, Milliman CL, Korsmeyer SJ. BCl-2 heterodimerizes in vivo with a conserved homolog, Bax, that accelerates programmed cell death. Cell 1993; 74: 609-619.

24. Wei MC, Zong WX, Cheng EHY, Lindsten T, Panoutsakopoulou V, Ross AJ et al. Proapoptotic $B A X$ and $B A K:$ a requisite gateway to mitochondrial dysfunction and death. Science 2001; 292: 727-730.

25. Kalkavan H, Green DR. MOMP, cell suicide as a BCL-2 family business. Cell death Diff 2018; 25: $46-55$.

26. Li P, Nijhawan D, Budihardjo I, Srinivasula SM, Ahmad M, Alnemri ES et al. Cytochrome $\mathrm{C}$ and datp-dependent formation of apaf-1/caspase- 9 complex initiates an apoptotic protease cascade. Cell 1997; 91: 479-489.

27. Marsden VS, O'Connor L, O'Reilly LA, Silke J, Metcalf D, Ekert PG et al. Apoptosis initiated by Bcl-2-regulated caspase activation independently of the cytochrome c/Apaf-1/caspase-9 apoptosome. Nature 2002; 419: 634-637.

28. Ekert PG, Read SH, Silke J, Marsden VS, Kaufmann H, Hawkins CJ et al. Apaf-1 and caspase-9 accelerate apoptosis, but do not determine whether factor-deprived or drugtreated cells die. J Cell Biol 2004; 165: 835-842.

29. White MJ, McArthur K, Metcalf D, Lane RM, Cambier JC, Herold MJ et al. Apoptotic caspases suppress mtDNA-induced STING-mediated type I IFN production. Cell 2014; 159: 1549-1562.

30. Metzstein MM, Stanfield GM, Horvitz HR. Genetics of programmed cell death in C. elegans past, present and future. Trends Genet 1998; 14: 410-416.

31. Huang DCS, Strasser A. BH3-Only proteins - essential initiators of apoptotic cell death. Cell 2000; 103: 839-842.

32. O'Connor L, Strasser A, O'Reilly LA, Hausmann G, Adams JM, Cory S et al. Bim: a novel member of the Bcl-2 family that promotes apoptosis. EMBO J 1998; 17: 384-395.

33. Bouillet P, Metcalf D, Huang DCS, Tarlinton DM, Kay TWH, Kontgen F et al. Proapoptotic Bcl-2 relative bim required for certain apoptotic responses, leukocyte homeostasis, and to preclude autoimmunity. Science 1999; 286: 1735-1738.

34. Nakano K, Vousden KH. PUMA, a novel proapoptotic gene, is induced by p53. Mol Cell 2001; 7: 683-694.

35. Yu J, Zhang L, Hwang PM, Kinzler KW, Vogelstein B. PUMA induces the rapid apoptosis of colorectal cancer cells. Mol Cell 2001; 7: 673-682.

36. Villunger A, Michalak EM, Coultas L, Mullauer F, Bock G, Ausserlechner MJ et al. p53- and drug-induced apoptotic responses mediated by BH3-only proteins puma and noxa. Science 2003; 302: 1036-1038.

37. Wei MC, Lindsten T, Mootha VK, Weiler S, Gross A, Ashiya M et al. tBID, a membranetargeted death ligand, oligomerizes BAK to release cytochrome c. Genes Dev 2000; 14: 2060-2071.

38. Conradt B, Horvitz HR. The c-elegans protein egl-1 is required for programmed cell death and interacts with the bcl-2-like protein ced-9. Cell 1998; 93: 519-529.

39. O'Neill KL, Huang K, Zhang J, Chen Y, Luo X. Inactivation of prosurvival Bcl-2 proteins activates Bax/Bak through the outer mitochondrial membrane. Genes Dev 2016; 30 : 973-988.

40. Merino D, Giam M, Hughes PD, Siggs OM, Heger K, O'Reilly LA et al. The role of BH3-only protein Bim extends beyond inhibiting Bcl-2-like prosurvival proteins. J Cell Biol 2009; 186: $355-362$.
41. Llambi F, Moldoveanu T, Tait SW, Bouchier-Hayes L, Temirov J, McCormick LL et al. A unified model of mammalian BCL-2 protein family interactions at the mitochondria. Mol Cell 2011; 44: 517-531.

42. Chou JJ, Li HL, Salvesen GS, Yuan JY, Wagner G. Solution structure of BID, an intracellular amplifier of apoptotic signaling. Cell 1999; 96: 615-624.

43. Li HL, Zhu H, Xu CJ, Yuan JY. Cleavage of bid by caspase 8 mediates the mitochondrial damage in the fas pathway of apoptosis. Cell 1998; 94: 491-501.

44. Luo X, Budihardjo I, Zou H, Slaughter C, Wang XD. Bid, a bcl2 interacting protein, mediates cytochrome $\mathrm{c}$ release from mitochondria in response to activation of cell surface death receptors. Cell 1998; 94: 481-490.

45. Ke F, Voss A, Kerr JB, O'Reilly LA, Tai L, Echeverry N et al. BCL-2 family member BOK is widely expressed but its loss has only minimal impact in mice. Cell Death Differ 2012; 19: 915-925

46. Ke F, Grabow S, Kelly GL, Lin A, O'Reilly LA, Strasser A. Impact of the combined loss of $\mathrm{BOK}, \mathrm{BAX}$ and $\mathrm{BAK}$ on the hematopoietic system is slightly more severe than compound loss of BAX and BAK. Cell Death Dis 2015; 6: e1938.

47. Llambi F, Wang YM, Victor B, Yang M, Schneider DM, Gingras S et al. BOK is a noncanonical BCL-2 family effector of apoptosis regulated by ER-associated degradation. Cell 2016; 165: 421-433.

48. Antonsson B, Conti F, Ciavatta A, Montessuit S, Lewis S, Martinou I et al. Inhibition of bax channel-forming activity by bcl-2. Science 1997; 277: 370-372.

49. Czabotar PE, Westphal D, Dewson G, Ma S, Hockings C, Fairlie WD et al. Bax crystal structures reveal how $\mathrm{BH} 3$ domains activate $\mathrm{Bax}$ and nucleate its oligomerization to induce apoptosis. Cell 2013; 152: 519-531.

50. Wiens M, Krasko A, Muller $\mathrm{Cl}$, Muller WE. Molecular evolution of apoptotic pathways: cloning of key domains from sponges (Bcl-2 homology domains and death domains) and their phylogenetic relationships. J Mol Evol 2000; 50: 520-531.

51. Degterev A, Yuan J. Expansion and evolution of cell death programmes. Nat Rev Mol Cell Biol 2008; 9: 378-390.

52. Vaux DL, Haecker G, Strasser A. An evolutionary perspective on apoptosis. Cell 1994; 76 $777-779$

53. Vaux DL, Hacker G. Hypothesis: apoptosis caused by cytotoxins represents a defensive response that evolved to combat intracellular pathogens. Clin Exp Pharmacol Physiol 1995; 22: 861-863.

54. Kayagaki N, Warming S, Lamkanfi M, Vande Walle L, Louie S, Dong J et al. Non-canonical inflammasome activation targets caspase-11. Nature 2011; 479: 117-121.

55. Ray CA, Black RA, Kronheim SR, Greenstreet TA, Sleath PR, Salvesen GS et al. Viral inhibition of inflammation: cowpox virus encodes an inhibitor of the interleukin-1 beta converting enzyme. Cell 1992; 69: 597-604.

56. Beidler DR, Tewari M, Friesen PD, Poirier G, Dixit VM. The baculovirus p35 protein inhibits Fas- and tumor necrosis factor-induced apoptosis. J Biol Chem 1995; 270: 16526-16528.

57. Tschopp J, Thome M, Hofmann K, Meinl E. The fight of viruses against apoptosis. Curr Opin Genet Dev 1998; 8: 82-87.

58. Upton JW, Kaiser WJ, Mocarski ES. Virus inhibition of RIP3-dependent necrosis. Cell Host Microbe 2010; 7: 302-313.

59. Vucic D, Kaiser WJ, Miller LK. Inhibitor of apoptosis proteins physically interact with and block apoptosis induced by drosophila proteins hid and grim. Mol Cell Biol 1998; 18: 3300-3309.

60. Trapani JA, Sutton VR, Granzyme B. pro-apoptotic, antiviral and antitumor functions. Curr Opin Immunol 2003; 15: 533-543.

61. Strasser A, Harris AW, Cory S. bcl-2 transgene inhibits T cell death and perturbs thymic selfcensorship. Cell 1991; 67: 889-999.

62. Vaux DL, Aguila HL, Weissman IL. Bcl-2 prevents death of factor-deprived cells but fails to prevent apoptosis in targets of cell mediated killing. Int Immunol 1992; 4 821-824.

63. Strasser A, Harris AW, Huang DC, Krammer PH, Cory S. Bcl-2 and Fas/APO-1 regulate distinct pathways to lymphocyte apoptosis. EMBO J 1995; 14: 6136-6147.

64. Newton K, Harris AW, Bath ML, Smith KG, Strasser A. A dominant interfering mutant of FADD/MORT1 enhances deletion of autoreactive thymocytes and inhibits proliferation of mature T lymphocytes. EMBO J 1998; 17: 706-718.

65. Scaffidi C, Fulda S, Srinivasan A, Friesen C, Li F, Tomaselli KJ et al. Two cd95 (apo-1/fas) signaling pathways. EMBO J 1998; 17: 1675-1687.

66. Jost PJ, Grabow S, Gray D, McKenzie MD, Nachbur U, Huang DC et al. XIAP discriminates between type I and type II FAS-induced apoptosis. Nature 2009; 460: 1035-1039.

67. Strasser A, Jost PJ, Nagata S. The many roles of FAS receptor signaling in the immune system. Immunity 2009; 30: 180-192.

68. Lowin B, Hahne M, Mattmann C, Tschopp J. Cytolytic T-cell cytotoxicity is mediated through perforin and Fas lytic pathways. Nature 1994; 370: 650-652.

69. Kagi D, Vignaux F, Ledermann B, Burki K, Depraetere V, Nagata S et al. Fas and perforin pathways as major mechanisms of T cell-mediated cytotoxicity. Science 1994; 265: 528-530.

70. Vaux DL, Strasser A. The molecular biology of apoptosis. Proc Natl Acad Sci USA 1996; 93 : 2239-2244.

71. Strasser A, Whittingham S, Vaux DL, Bath ML, Adams JM, Cory S et al. Enforced BCL2 expression in B-lymphoid cells prolongs antibody responses and elicits autoimmune disease. Proc Natl Acad Sci USA 1991; 88: 8661-8665. 
72. Kayagaki N, Stowe IB, Lee BL, O'Rourke K, Anderson K, Warming S et al. Caspase-11 cleaves gasdermin D for non-canonical inflammasome signalling. Nature 2015; 526: 666-671.

73. Shi J, Zhao Y, Wang K, Shi X, Wang Y, Huang $\mathrm{H}$ et al. Cleavage of GSDMD by inflammatory caspases determines pyroptotic cell death. Nature 2015; 526: 660-665.

74. Rongvaux A, Jackson R, Harman CC, Li T, West AP, de Zoete MR et al. Apoptotic caspases prevent the induction of type I interferons by mitochondrial DNA. Cell 2014; 159 : 1563-1577.

75. Kultz D. Molecular and evolutionary basis of the cellular stress response. Annu Rev Physiol 2005; 67: 225-257.
76. Tsujimoto $Y$. Stress-resistance conferred by high level of bcl-2 alpha protein in human $B$ lymphoblastoid cell. Oncogene 1989; 4: 1331-1336.

77. Roberts AW, Davids MS, Pagel JM, Kahl BS, Puvvada SD, Gerecitano JF et al. Targeting BCL2 with venetoclax in relapsed chronic lymphocytic leukemia. N Engl J Med 2016; 374: 311-322.

78. Souers AJ, Leverson JD, Boghaert ER, Ackler SL, Catron ND, Chen J et al. ABT-199, a potent and selective BCL-2 inhibitor, achieves antitumor activity while sparing platelets. Nat Med 2013; 19: 202-208.

79. Kotschy A, Szlavik Z, Murray J, Davidson J, Maragno AL, Le Toumelin-Braizat G et al. The MCL1 inhibitor $\mathbf{5 6 3 8 4 5}$ is tolerable and effective in diverse cancer models. Nature 2016; 538 : $477-482$. 